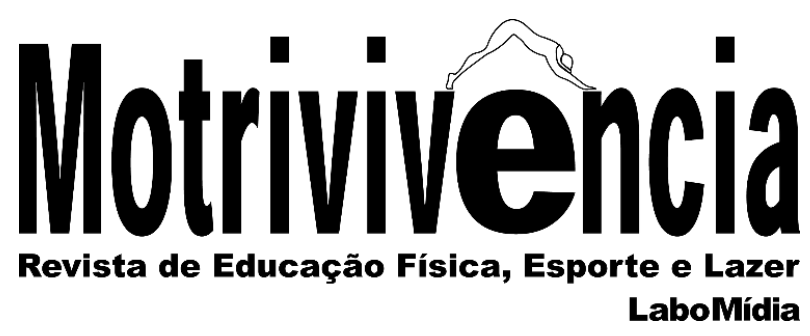

\title{
Mulheres de preto: trajetórias na arbitragem do futebol profissional
}

\section{RESUMO}

O presente estudo diz sobre o baixo número de árbitras que atuam no futebol brasileiro e as barreiras que estas enfrentam para se manterem apitando nos motivam a analisar as trajetórias de árbitras no futebol brasileiro, a fim de desvendar possíveis questões de gênero implicadas nesse campo. Utilizamos a história oral temática como metodologia e a entrevista com dez árbitras como instrumento de coleta dos dados. Os resultados apontam que elas tiveram diferentes vivências esportivas e iniciaram a carreira contando com o apoio da família e de outras mulheres referência. Atuando em competições nacionais e internacionais, as árbitras que iniciaram na arbitragem nas décadas de 1980 e 1990 foram pioneiras, rompendo barreiras e deixando como legado o campo de atuação mais acessível às suas sucessoras.

PALAVRAS-CHAVE: Árbitra de futebol; Gênero; Futebol; Arbitragem
Igor Chagas Monteiro

Doutorando em Educação Física Universidade Federal de Juiz de Fora, Faculdade de Educação Física e Desportos, Juiz de Fora, Minas Gerais, Brasil igorcmonteiroef@gmail.com ${ }^{\circ}$ https://orcid.org/0000-0002-0643-1261

Mariana Cristina Borges Novais Mestra em Educação Física Universidade Federal de Juiz de Fora, Faculdade de Educação Física e Desportos, Juiz de Fora, Minas Gerais, Brasil maribnovais@hotmail.com ๑ https://orcid.org/0000-0001-6638-0729

João Paulo Fernandes Soares

Doutorando em Educação Física Universidade Federal de Juiz de Fora, Departamento de Educação Física, Governador

Valadares, Minas Gerais, Brasil joaopaulosoaresufjf@gmail.com https://orcid.org/0000-0002-0992-2795

Ludmila Mourão

Doutora em Educação Física Universidade Federal de Juiz de Fora, Faculdade de

Educação Física e Desportos, Juiz de Fora, Minas Gerais, Brasil mouraoln@gmail.com - $\underline{\text { https://orcid.org/0000-0003-0893-7511 }}$

Women in black: careers on professional soccer

\author{
ABSTRACT \\ Motrivivência, (Florianópolis), v. 32, n. 63, p. 01-15, julho/dezembro, 2020. Universidade Federal de Santa Catarina. \\ ISSN 2175-8042. DOI: https://doi.org/10.5007/2175-8042.2020e72680
}


This study is about the lower number of female referees working in Brazilian soccer and the barriers they face to keep on the field motivates us to analyze the careers of female referees in Brazilian soccer to unveil possible gender issues in this area. We used the thematic oral history as methodology and the interview with ten female referees to collect data. The results indicate that they had different sports experiences and started their careers with the support of their families and other women referees. Acting in national and international competitions, the women who began in refereeing in the 1980s and 1990s were pioneers, breaking barriers and leaving the field more accessible to their successors as legacy.

KEYWORDS: Woman soccer referee; Gender; Soccer; Refereeing

\section{Mujeres de negro: carrera sen el fútbol profesional}

\section{RESUMEN}

El estudio es sobre el bajo número de árbitras que trabajan en fútbol brasileño y las barreras que enfrentan para seguir actuando nos motivan a analizar las carreras de árbitras en el fútbol brasileño $\mathrm{y}$ posibles problemas de género en este campo. Utilizamos la historia oral temática como metodología y la entrevista con las diez árbitras participantes del estudio como instrumento de recolección de datos. Los resultados indican que tuvieron diferentes experiencias deportivas y comenzaron sus carreras con el apoyo de sus familias y otras "mujeres de referencia". Actuando en competiciones nacionales e internacionales, las árbitras que comenzaron en arbitraje en los años 1980 y 1990 fueron pioneras, rompieron barreras y dejaron como legado el campo de actuación más accesible para sus sucesoras.

PALABRAS-CLAVE: Árbitra de fútbol; Género; Fútbol; Arbitraje 


\section{INTRODUÇÃO}

A chegada das mulheres brasileiras no campo esportivo como atletas, treinadoras, gestoras e árbitras não foi fácil. Embora a crescente participação das mulheres nesse cenário seja hoje uma realidade, há que se considerar as diferenças de visibilidade conferida a elas no âmbito esportivo, o abismo na remuneração e o grande desafio na equidade de oportunidades (GOELLNER, 2006).

A arbitragem em futebol no Brasil surge junto com a chegada da modalidade ao país em 1894. Mas, sobre a participação das mulheres como árbitras, ainda pairam muitas imprecisões devido à carência de registros (SILVA; RODRIGUEZ-AÑEZ; FROMETA, 2002).

Os relatos de Léa Campos parecem ser os primeiros a visibilizarem mulheres exercendo esta função. Léa revela, em sua biografia, que fez o curso de arbitragem em 1967 na Federação Mineira de Futebol, mas só foi diplomada e reconhecida como árbitra pela Confederação Brasileira de Desportos em 1971, quando recebeu o convite para atuar no campeonato mundial de futebol de mulheres, no México. Nesse mesmo ano, Léa Campos recebeu o "apito de ouro" da FIFA e foi reconhecida como a primeira árbitra de futebol do mundo (ROMERO, 1999, p.72).

A década de 1980 trouxe avanços para esse campo, com o desenvolvimento de um curso de arbitragem exclusivo para mulheres, realizado em 1983, na Universidade Estadual do Rio de Janeiro (UERJ), pela Associação de Árbitros do Rio de Janeiro. Cláudia Guedes, formada nesse curso, se tornou a primeira mulher a apitar uma partida de competição organizada pela FIFA, na Copa do Mundo de Futebol de mulheres em 1991, realizada na China.

Ainda na década de 1980, Sílvia Regina se formou árbitra na cidade de Mauá (SP), ingressando no quadro da Federação Paulista de Futebol somente em 1997 e, em 2003, se tornou a primeira mulher a apitar uma partida da Copa Sul-Americana masculina. No mesmo ano, compôs, ao lado de Aline Lambert e Ana Paula Oliveira, o primeiro trio de árbitras a atuar em partidas do Campeonato Brasileiro masculino Série A (REIS; ARRUDA, 2011).

Isso posto, observa-se no estudo de Stahlberg (2011) que a presença e a visibilidade de mulheres na arbitragem, mesmo que ainda de forma tímida, representa a entrada e ocupação delas nesse campo. $\mathrm{O}$ estudo que debate a presença das mulheres no futebol como torcedoras, jornalistas, psicólogas e árbitras aponta que nos cursos da Escola de Arbitragem da Federação Paulista de Futebol (FPF) em 2007/2008, dos 136 inscritos, 129 eram homens e 7 eram mulheres. E, em 2008/2009, a pesquisa revela um pequeno aumento do número de mulheres inscritas, de 7 para 12 (STAHLBERG, 2011).

\footnotetext{
${ }^{1}$ Prêmio que recebeu da FIFA por ter sido reconhecida como a primeira árbitra de futebol do mundo.
} 
Em levantamento realizado no site da Confederação Brasileira de Futebol (CBF) em 2014, Monteiro, Soares e Mourão (2015) verificaram a presença de 61 árbitras assistentes e 13 árbitras centrais no quadro da $\mathrm{CBF}$, o que demonstra ainda uma sub-representação de árbitras brasileiras $(15,48 \%)$ em relação aos árbitros $(84,52 \%)$. Os dados levantados pelas jornalistas do Portal Dibradoras, em 2019, apontam um quantitativo de 86 mulheres, divididas nas funções de árbitras, árbitras assistentes e analistas de desempenho de arbitragem no quadro nacional, confirmando que a sub-representatividade das mulheres permanece, já que elas ocupam apenas 10,28\% do quadro de arbitragem da $\mathrm{CBF}^{2}$.

Podemos dizer que, ao longo da história, o futebol, considerado uma paixão nacional, se manteve como uma prática desportiva de hegemonia masculina no Brasil em todas as funções que dele se derivam, como apontado por diversos autores, jornalistas e cronistas brasileiros (BATISTA; DEVIDE, 2009).

Nesse sentido, nos interessa neste estudo analisar as trajetórias ${ }^{3}$ de árbitras no futebol brasileiro, com a intenção de desvendar possíveis questões de gênero ${ }^{4}$ implicadas no número reduzido de árbitras que atuam no futebol brasileiro e nas barreiras que estas mulheres enfrentaram e enfrentam para se manterem no campo.

\section{PERCURSOS METODOLÓGICOS}

Esta pesquisa se alinha com o método da história oral temática, que "se compromete com o esclarecimento ou opinião dos entrevistados sobre algum evento definido. [...]. Detalhes da história pessoal do narrador interessam na medida em que revelam aspectos úteis à compreensão da temática do estudo" (MEIHY, 2005, p.162).

Desse modo, no processo de pesquisa de campo, elegemos a entrevista semiestruturada como técnica de coleta de dados. Segundo Costa e Costa (2012), essa entrevista é realizada a partir de um roteiro de perguntas abertas ${ }^{5}$, e pode ser realizada pessoalmente, por telefone ou via internet.

\footnotetext{
2 Matéria das jornalistas do Portal Dibradoras sobre árbitras de futebol (2019). Disponível em: https://dibradoras.blogosfera.uol.com.br/2019/02/12/para-alem-das-encaradas-vida-de-arbitra-tem-ate-sabotagem-emteste-fisico/. Acesso em: 15 mar. 2020.

${ }^{3}$ Pensamos "trajetórias" a partir da concepção de habitus de Bourdieu, definido como: “[...] sistema de disposições socialmente constituídas que, enquanto estruturas estruturadas e estruturantes, constituem o princípio gerador e unificador do conjunto das práticas e das ideologias características de um grupo de agentes (BOURDIEU, 2011, p.191).

${ }^{4}$ Aqui compreendemos gênero a partir dos escritos de Joan Scott (1995). O gênero é "um elemento constitutivo de relações sociais baseadas nas diferenças percebidas entre os sexos" e "uma forma primária de dar significado às relações de poder" (SCOTT, 1995, p.86).

${ }^{5} \mathrm{O}$ roteiro de entrevista versou sobre a inserção e permanência na arbitragem em futebol. As entrevistas foram gravadas em áudio. Antes da realização das entrevistas, foi coletada a assinatura do Termo de Consentimento Livre e Esclarecido (TCLE) das participantes. Após a realização das entrevistas, procedeu-se a transcrição na íntegra, respeitando todas as formas discursivas apresentadas pelas participantes.
} 
Em nossa pesquisa, as entrevistas foram realizadas seguindo um roteiro, sua gravação em áudio, seguido de transcrição na íntegra e revisão.

No processo de análise das entrevistas, buscamos estabelecer diálogos com referências bibliográficas e artigos científicos, dados disponibilizados em sites de federações e matérias em jornais online.

O grupo de colaboradoras da pesquisa foi composto por dez mulheres (cinco árbitras e cinco ex-árbitras $)^{6}$, com atuação em competições nacionais e internacionais e com experiências na arbitragem variando entre dez e vinte e sete anos.

O estudo respeitou os princípios éticos e foi aprovado pelo Comitê de Ética em Pesquisa com Seres Humanos da Universidade Federal de Juiz de Fora (UFJF), sob o parecer $n^{\circ}$ CAAE 43035515.5.0000.5147. Todas as colaboradoras autorizaram a identificação de seus nomes no relatório da pesquisa e, assim, este artigo irá identificá-las a fim de conferir visibilidade às suas trajetórias.

Essas colaboradoras foram subdivididas em dois grupos, segundo o ano de formação na arbitragem. Percebemos que as dificuldades enfrentadas por árbitras formadas em tempos diversos foram diferentes. O objetivo com este agrupamento foi melhorar a inteligibilidade da análise dos dados empíricos. Dessa forma, denominamos G1 o grupo de árbitras que se formou na arbitragem entre 1980 e 1998 (quatro ex-árbitras), e G2 o grupo de árbitras formado a partir do ano 2000 (cinco árbitras e uma ex-árbitra).

As colaboradoras do G1 são solteiras, com idades que variam entre 36 e 53 anos. Três delas possuem curso superior completo e chegaram ao quadro de arbitragem da FIFA. O tempo dedicado à arbitragem variou de treze a vinte e sete anos.

As colaboradoras do G2 são todas solteiras, com idades entre 29 e 41 anos, e o ano de formação na arbitragem foi entre 2000 e 2005. Todas possuem ensino superior completo, sendo duas delas pós-graduadas. Três delas já haviam integrado ou integravam o quadro da FIFA no momento da entrevista. O tempo dedicado à arbitragem variou entre dez e quinze anos.

As colaboradoras do G1 e G2, em sua maioria, iniciaram sua trajetória em ligas de futebol amador (Rio de Janeiro, Minas Gerais e São Paulo) e em federações estaduais de Minas Gerais e São Paulo.

A partir das narrativas das entrevistadas emergiram dois temas que nortearam nossa análise: a aproximação das árbitras com o esporte, inserção e permanência na arbitragem em futebol e; a

${ }^{6}$ As entrevistas foram realizadas presencialmente, por telefone e via internet, atendendo às disponibilidades e solicitações das colaboradoras, em 2015. 
carreira das árbitras, suas atuações nas categorias de base e nas competições nacionais e internacionais.

\section{AS TRAJETÓRIAS DAS ÁRBITRAS: aproximações com o esporte, inserção e permanência na arbitragem}

Uma das primeiras vias de acesso para as experiências no esporte e a inserção na arbitragem de nossas colaboradoras de G1 e G2 compreende as práticas de atividades físicas e esportivas na infância, como futebol, voleibol, futsal, handebol e ginástica artística. Entre as duas árbitras que tiveram experiências com o futebol, os pais foram os motivadores. As experiências esportivas de torcedora vivenciada nas arquibancadas de estádio de futebol com o pai e a ida ao campo para atuar como anotadora nos jogos em que o pai apitava, constituíram a trajetória de envolvimento com o esporte dessas mulheres. Esses pontos de conexão com o esporte na infância foram fundamentais para o desenvolvimento do gosto pelo esporte e a sua futura identificação com a arbitragem.

O relato de Tatiane Sacilotti $(\mathrm{G} 2,2015)$, árbitra de 29 anos, chama a atenção por trazer inúmeras experiências na infância que a identificaram com o futebol: "Nunca joguei futebol para competir. Foi mais em escola mesmo, na rua de casa. Eu era praticamente a única menina que jogava bola com os meninos. A minha paixão pelo futebol é desde a infância” (Tatiane Sacilotti, G2, 2015).

A narrativa de Tatiane mostra como as meninas estão distantes da prática do futebol e o quanto o futebol é culturalmente um jogo de meninos desde a infância.Arlei Damo (2006), em uma etnografia observando meninos e meninas praticantes de futebol, identificou poucas ou quase nenhuma menina nos jogos. O autor argumenta que as meninas parecem ser uma ameaça ao futebol, pois podem ressignificar certos acontecimentos do jogo, podendo inclusive tirar a sua conotação masculina (DAMO, 2006).

Nesse cenário, emerge a seguinte questão: o que as levou à arbitragem? As respostas que encontramos, fruto das narrativas das colaboradoras, foram: o gosto pelo futebol, a oportunidade de envolvimento com o esporte e a família para as árbitras do grupo G1. As árbitras do grupo G2, embora também tenham valorizado o gosto pelo futebol, a oportunidade e a família, trazem outra resposta relevante que se destacou em suas falas: a mulher referência. Ou seja, o fato de terem visto uma árbitra atuando no campo de futebol chamou sua atenção e motivou seu interesse pela arbitragem. Pudemos constatar que as árbitras que se inseriram na arbitragem na década de 1980 foram fonte de inspiração para aquelas mais jovens que se inseriram no século XXI.

A narrativa de Cláudia Guedes (53 anos) mostra como o gosto pelo futebol e a vontade de atuar como técnica de futebol a ajudaram a se decidir pela arbitragem: 
Eu queria ser técnica, eu estava estudando para isso na faculdade e aí surgiu esse curso de formação de árbitras [...] e eu me inscrevi. Achei que seria um caminho para que chegasse ao mundo do futebol. Começasse a ficar inserida no mundo do futebol e ajudasse na minha formação para técnica (Cláudia Guedes, G1, 2015).

Os relatos de Cláudia (G1, 2015) e de Graziele Crizol (G2, 2015), que pensava em "entrar como preparadora física em algum time de futebol", são evidências das barreiras e das interdições que sofrem as mulheres para se inserirem em cargos técnicos (treinadora e preparadora física) no futebol brasileiro. Em pesquisa recente, Novais (2018) mostrou as barreiras enfrentadas pelas treinadoras para se inserirem no futebol associadas a dificuldades para permanecerem atuando e para ascenderem no cargo. Os relatos das treinadoras sinalizam para recorrentes discursos relacionados à desconfiança sobre a competência da mulher para ocupar cargos de liderança. E, após a sua inserção no cargo, mesmo com formação superior e alta capacitação técnica, elas têm que provar alto desempenho e competência no cargo a todo momento. A necessidade de ter outro emprego, devido aos baixos salários e à baixa oportunidade de ascensão ao futebol masculino, são dificuldades apontadas pelas treinadoras (NOVAIS, 2018).

Outros dados que conferem evidências a esse cenário foram os encontrados no estudo realizado pelo sindicato dos jogadores de futebol (FIFPro) ${ }^{7}$, em 2018, mostrando que 49\% das jogadoras de futebol de elite (em 33 países pesquisados) não recebem salários e que 87\% delas encerrarão a carreira antes dos 25 anos. Os salários mais baixos ofertados às treinadoras no futebol de mulheres em relação aos treinadores no futebol de elite masculino (NOVAIS, 2018) parecem nos mostrar que os problemas de remuneração estão presentes nos diferentes cargos ocupados por mulheres no futebol.

A carreira na arbitragem, embora ainda apresente problemas e interdições às mulheres, parece apresentar mais oportunidades de inserção e uma remuneração um pouco melhor comparada a outras funções que elas pudessem exercer dentro do futebol (STAHLBERG, 2011), como jogadoras, treinadoras ou preparadoras físicas. O relato da árbitra assistente e pesquisadora Ineildes Santos (2013), em seu artigo sobre árbitras de futebol, mostra que as árbitras do quadro da CBF atuavam três vezes por mês, recebendo cerca de $\mathrm{R} \$ 350,00$ por partida, totalizando uma média de $\mathrm{R} \$ 1.050,00$. Os árbitros do mesmo quadro auferiam aproximadamente $\mathrm{R} \$ 6.000,00$ mensais (SANTOS, 2013). Isso nos mostra uma diferença significativa na remuneração e, ainda, que problemas de gênero estão presentes na arbitragem e nos diferentes cargos em que as mulheres estão presentes no futebol.

\footnotetext{
${ }^{7}$ Matéria da Agência Brasil. Disponível em: https://agenciabrasil.ebc.com.br/internacional/noticia/2018-07/estudo-
} aponta-que-49-das-jogadoras-de-futebol-nao-recebe-salarios. Acesso em: 30 mar. 2020. 
A família foi outra via de acesso importante para o grupo G2, uma vez que pais e irmãos, atuando como árbitros e/ou gostando de futebol, favoreceram o início das experiências delas na arbitragem. A fala de Regildenia Moura (41 anos) traz suas experiências esportivas na família e revela como, através de seu irmão, ex-jogador e árbitro, se aproximou do futebol desde a infância:

A arbitragem entrou na minha vida pela forma como fui criada em casa. Porque eu sou de uma família de 6 irmãos, onde tem 4 mulheres e 2 homens. Como os dois caçulas éramos o Eraldo e eu, e meu irmão é apaixonado por futebol, por esporte [...]. E aí nasceu a minha vontade de conhecer mais o esporte, ele sempre jogava bola, eu ia vê-lo jogar, depois ele machucou o joelho e não podia jogar mais. Ele fez o curso de árbitro e foi arbitrar partidas de futebol e eu sempre ia vê-lo apitar jogos de futebol (Regildenia Moura, G2, 2015).

As narrativas nos mostram que os homens da família das árbitras desta pesquisa divergem das normas de gênero, quando as apresentam ao mundo do futebol, tradicionalmente de "reserva masculina", e incentivam e valorizam suas qualidades para atuar no esporte.

A família é importante para o incentivo das mulheres no esporte em diferentes fases da vida, desde a iniciação esportiva até a escolha pelo esporte a ser praticado, conforme observamos em estudos de diversas modalidades esportivas, como o judô (SOUZA; MOURÃO, 2011), as lutas (FERNANDES, 2014), o voleibol (TAVARES, 2015) e principalmente em modalidades interditadas a elas, como o futebol (LIMA, 2013).

Outro fator citado por nossas árbitras foi a oportunidade para ingressar na arbitragem. Janette Arcanjo (34 anos) destacou a realização de um curso de arbitragem em futebol no ano 2000 em Ipatinga (MG), onde ela residia: “eu vi um cartaz na padaria, falando que pela primeira vez ia ser [um curso] extensivo às mulheres, aí resolvi fazer" (Janette Arcanjo, G2, 2015).

Para as árbitras do grupo G2, pudemos perceber como o pioneirismo das árbitras pertencentes ao grupo G1, que desbravaram o campo da arbitragem nas décadas de 1980 e 1990 em tempos de interdição às mulheres nos gramados, foi importante para os processos de inserção de outras mulheres na arbitragem.

As mulheres referência no estudo de Silva, Botelho-Gomes e Goellner (2013) apontam para processos de empoderamento das mulheres dentro do subcampo da arbitragem no esporte. Assim, percebemos como é fundamental que as mulheres tenham outras mulheres como referência em cargos nos quais elas estão sub-representadas. A narrativa de Tatiane Sacilotti (G2, 2015) demonstra o papel desse empoderamento, que fez com que ela descobrisse a arbitragem e a possibilidade de atuar na área: “Amor à primeira vista (risos). Eu me encantei quando eu descobri a arbitragem feminina, que foi em 2003, com a Sílvia Regina, a Aline e a Ana Paula Oliveira. E, quando eu vi, decidi naquele dia que eu iria me tornar árbitra" (Tatiane Sacilotti, G2, 2015). 
Aqui é visível a importância das mulheres árbitras atuando no futebol como formadoras de novas possibilidades, exercendo uma função de tomada de decisão, ocupando uma posição de comando dentro do campo de futebol e subvertendo o ideário masculino da arbitragem. A visibilidade conferida à participação das mulheres no esporte contribui também para o desenvolvimento da atividade - no caso, a arbitragem - assim como para a emancipação das mulheres (GOELLNER; SILVA; BOTELHO-GOMES, 2013).

A diferença que encontramos entre os grupos de mulheres de G1 e G2 reside no fato de que as primeiras foram pioneiras, enfrentaram interdições, foram desafiadas, enfrentaram preconceitos em campo, foram levantadas dúvidas sobre sua competência, foram tiradas de campo, e aquelas que fizeram parte do grupo G2 já encontraram um cenário mais favorável para atuar, embora ainda preconceituoso. Ou seja, a oportunidade é fundamental para que se altere o campo hierárquico de gênero e também a visibilidade.

\section{A CARREIRA DAS ÁRBITRAS: das atuações nas categorias de base às competições nacionais e internacionais}

As carreiras das árbitras entrevistadas neste estudo se iniciaram em partidas de futebol amador e de categorias de base ${ }^{8}$ masculinas, conforme relata Renata Ruel (36 anos): "Aí entramos para o quadro de árbitros e você vai galgando, vai começando pelas categorias de base [masculinas], sub-15, sub-17, o feminino, até você chegar no profissional [masculino] e ir subindo cada vez mais, dentro do possível” (Renata Ruel, G2, 2015).

As atuações delas nessas partidas foram analisadas por observadores das federações in loco que elaboraram relatórios sobre suas decisões técnicas e disciplinares. As boas atuações foram importantes para uma ascensão ao futebol profissional, como destaca Cássia Dias (47 anos):

"Eu acho que as boas arbitragens que eu fiz. Igual eu te falei, a partir desse jogo aí [jogo em que o árbitro machucou e ela apitou bem a partida], que ele [o diretor de arbitragem] começou a me dar mais oportunidades" (Cássia Dias, G1, 2015).

As árbitras do grupo G1 estiveram presentes em importantes competições internacionais, destacando-se a atuação de Cláudia Guedes no futebol de mulheres na Copa do Mundo da China (1991) e nas Olimpíadas de Atlanta (1996) e, posteriormente, de Ana Paula Oliveira e Sílvia Regina nos Jogos Olímpicos de Atenas (2004).

As árbitras do grupo G2 atuaram em sua maioria em competições nacionais, como os campeonatos brasileiros (masculino e feminino) e a Copa do Brasil (masculina e feminina).

${ }^{8}$ Para as federações estaduais, os campeonatos de categoria de base são considerados como pertencentes ao futebol amador. 
Observamos, assim como Santos e Messeder (2016), que as árbitras deste estudo costumam atuar com mais frequência em competições internacionais de futebol para mulheres, e nos campeonatos masculinos elas têm presença rara.

Para chegar a atuar nas partidas de futebol masculino profissional elas são escaladas pelas federações a que estão vinculadas. Entre as pessoas importantes para a consolidação de suas carreiras, os relatos das árbitras tanto do grupo G1 quanto do G2 apontam os dirigentes de arbitragem. O relato de Sílvia Regina de Oliveira $(G 1,2015)$ exemplifica muito bem essa questão:

As pessoas que me designaram [foram relevantes para a consolidação da minha carreira]. Armando Marques, que foi a pessoa que mais me deu jogos, que mais me deu oportunidades nos grandes jogos, com certeza, a maior figura de representatividade para mim. E aquelas que me apoiaram no início da carreira, como os dirigentes da Federação Paulista de Futebol, que começaram a me escalar no futebol profissional (Sílvia Regina de Oliveira, G1, 2015).

Nessa fala é possível verificar a importância da tutoria, em que o(a) tutor(a) pode ser entendido(a) como aquele(a) que faz o convite e/ou facilita o acesso ao cargo (KILTY, 2006; FERREIRA et al., 2013). É interessante observar como as relações com os dirigentes de arbitragem, embora por vezes conflituosas, são de fundamental importância para ascensão e escalação das árbitras nos jogos. Os dirigentes das federações, comissões de arbitragem e observadores de arbitragem tendem a manter um percentual majoritário de homens atuando.

Pode-se verificar também um baixo número de mulheres como árbitras centrais, já que a maioria delas opta por ser árbitra assistente, conforme narra Regildenia Moura (41 anos).

“As árbitras assistentes já têm mais oportunidades, você percebe pelo número de árbitras centrais e árbitras assistentes. Porque pelas oportunidades que têm então as mulheres que fazem o curso de arbitragem preferem bandeirar do que apitar” (Regildenia Moura, G2, 2015).

Essa decisão parece ser, de forma velada, influenciada pelas dificuldades que o campo lhes impõe para atuarem como árbitras. A decisão de ser árbitra central significa resistência, subversão da ordem do futebol tradicional, e vai contra as decisões da maioria dos dirigentes que posicionam as árbitras como assistentes, as "bandeirinhas".

Para a consolidação da carreira, os fatores declarados importantes pelas árbitras do grupo G1 foram boas atuações, preparação física e técnica, persistência e a capacidade em superar dificuldades. Para o grupo G2, o fator preponderante foi a preparação física e técnica, devido às exigências do teste físico, instituído em 2001 e reformulado em 2006.

Cumpre destacar que a inserção das árbitras nas décadas de 1980 e 1990 é anterior às novas formulações de teste físico: o teste físico era o teste de Cooper, que não exigia um treinamento tão extenuante para aprovação. Entretanto, no ano de 2001, a FIFA estabeleceu uma nova sequência de 
provas anaeróbias, uma de velocidade e outra de resistência, trazendo os índices masculinos e femininos. Então, em janeiro de 2006, a FIFA estabeleceu, através da circular $n^{0}$ 1013, um novo modelo de testes físicos para árbitras(os), que entrou em vigor a partir de 2007. Portanto, "a árbitra e a árbitra assistente, para atuar em competições masculinas deverão alcançar os índices estabelecidos, respectivamente para o quadro masculino" (FIFA, 2007)9.

Quanto às dificuldades relatadas pelas árbitras nos testes físicos, percebe-se que elas têm de superar barreiras diariamente para se manterem no quadro de arbitragem das federações e da confederação, com treinamentos exaustivos para conseguirem o índice masculino, conforme vemos na fala de Francielli Bento (32 anos):

Quando você vira árbitra internacional, uma árbitra FIFA ou até mesmo CBF, você é árbitra 24 horas do seu dia. Você levanta pensando no seu treino, você deita pensando no seu treino, pensando em testes [físicos], pensando nos cursos, pensando em tudo voltado para a arbitragem (Francielli Bento, G2, 2015).

Ineildes Santos e Suely Messeder (2016) afirmam que, no ano de 2008, apenas uma mulher (uma árbitra assistente) foi aprovada no teste masculino. Quando elas foram questionadas sobre como conciliar as demandas da arbitragem com a vida pessoal, tanto as participantes do grupo G1 quanto do G2 afirmaram ter dificuldades, declarando a ausência em eventos de família, pouco tempo para relacionamento afetivo e lazer, dificuldade em conciliar a arbitragem com a vida profissional e com os estudos. Uma fala que exemplifica essa dificuldade é da árbitra Ana Paula Oliveira (36 anos):

"Eu encarava como profissional, por mais amador que nós fossemos. E eu trazia isso para a minha vida, para o meu dia a dia. Então, assim, conversava com a família, até porque datas importantes como aniversário, dia das mães, que me perdoassem pela ausência” (Ana Paula Oliveira, G1, 2015).

É importante demarcar que as árbitras dos anos 1980 e 1990 relataram menos dificuldades para conciliar as demandas de tempo pela não existência de testes físicos e menor número de jogos. Já as árbitras da década de 2000 (G2) apresentaram maior dificuldade em função dos treinamentos para os testes físicos e maior número de jogos que implicam em mais viagens e dedicação.

As narrativas demonstram uma alta demanda de horas de trabalho, com viagens para os jogos, "reciclagens", treinamentos físicos e técnicos. Kilty (2006) encontrou, ao investigar as barreiras enfrentadas pelas técnicas esportivas na América do Norte, que a alta demanda de horas de trabalho é uma barreira significativa correlacionada ao desejo de ser técnica esportiva. Essa demanda interfere no tempo pessoal e no tempo dedicado à família. Esse cenário se repete no caso das árbitras de nossa

${ }^{9}$ Circular n ${ }^{\mathrm{o}} 1104$ da FIFA de 15 de agosto de 2007. 
pesquisa e se mostra crítico em relação ao papel da mulher na arbitragem e na vida familiar, mesmo sabendo que todas as entrevistadas são solteiras.

\section{ALGUMAS CONSIDERAÇÕES}

Com este estudo sobre as trajetórias de árbitras brasileiras das décadas de 1980, 1990 e 2000 foi possível concluir que as carreiras das árbitras entrevistadas se iniciaram após experiências esportivas diversas e com apoio da família. Nota-se que os homens da família, ao oferecerem oportunidades às mulheres de se aproximarem do futebol, rompem com uma hierarquia de gênero tradicionalmente instituída no ambiente familiar.

As mulheres referência ressignificam as possibilidades de carreira para as jovens árbitras, cuja visibilidade contribui para que essas mulheres se reconheçam nos cargos das pioneiras e tenham a possibilidade de se tornarem árbitras de futebol nos maiores estádios do Brasil e do mundo.

As trajetórias nos gramados começam com boas atuações em partidas de categorias de base associadas à experiência adquirida no futebol amador. A passagem para o futebol profissional vem com a indicação dos diretores de arbitragem através de relatórios de atuação das árbitras e esse início ocorre nos campeonatos estaduais masculinos.

A consolidação da carreira das árbitras das décadas de 1980 e 1990 é marcada pela preparação física e técnica, persistência e a capacidade de superar dificuldades e, para as árbitras do início do século XXI, pela preparação física e treinamento de alto nível em função das exigências do novo teste físico da FIFA. As árbitras deste estudo participaram das mais importantes competições nacionais e internacionais, fato que merece reconhecimento e destaque.

A dificuldade em conciliar as demandas da arbitragem com a vida pessoal foi uma unanimidade, o que sinaliza a importância de um debate no campo da arbitragem acerca do reconhecimento da profissão de árbitra de futebol.

Enfim, cabe pontuar que nos interessa explicitar os protagonismos de importantes mulheres na arbitragem que subvertem normas de gênero e papéis sociais. Recomenda-se outras pesquisas, levantamentos do quantitativo de árbitras nas federações estaduais e trajetórias de mulheres em campeonatos estaduais, regionais, nacionais e internacionais.

\section{REFERÊNCIAS}

ANDRES, Suélen de Souza; GOELLNER, Silvana Vilodre. Trajetórias esportivas de jogadoras de handebol e suas narrativas sobre ser profissional da modalidade. Movimento, Porto Alegre, v. 24, n. 2, p. 527-538, 2018. 
BATISTA, Renata Silva; DEVIDE, Fabiano Pries. Mulheres, futebol e gênero: reflexões sobre a participação feminina numa área de reserva masculina. Revista EF Deportes, Buenos Aires, v. 14, n. 137, 2009.

BOURDIEU, Pierre. A economia das trocas simbólicas. 7. ed. São Paulo: Perspectiva, 2011.

COSTA, Marco Antônio Ferreira da; COSTA, Maria de Fátima Barrozo da. Projeto de pesquisa: entenda e faça. Petrópolis: Vozes, 2012.

DAMO, Arlei Sander. As dramatizações do gênero numa configuração futebolística. Seminário Fazendo Gênero: Práticas corporais e esportivas. ST21. Anais [...] Florianópolis: Universidade Federal de Santa Catarina, 2006, p.1-7.

FERNANDES, Vera. Mulheres de ouro: trajetória e representações de atletas de lutas. 2014. 185 f. Dissertação (Mestrado em Educação Física) - Faculdade de Educação Física e Desportos, Universidade Federal de Juiz de Fora, Juiz de Fora, 2014.

FERREIRA, Heidi Jancer. et al. A baixa representatividade de mulheres como técnicas esportivas no Brasil. Movimento, Porto Alegre, v. 19, n. 3, p. 103-124, mar. 2013.

GOELLNER, Silvana Vilodre. Mulher e Esporte no Brasil: entre incentivos e interdições elas fazem história. Pensar a Prática, Goiânia, v. 8, n. 1, p. 85-100, 2006.

GOELLNER, Silvana Vilodre; SILVA, Paula; BOTELHO-GOMES, Paula. A sub-representação do futebol praticado por mulheres no jornalismo esportivo de Portugal: um estudo sobre a Algarve Women's Football Cup. Movimento, Porto Alegre, v. 19, n. 3, p. 171-189, jul./set. 2013.

KILTY, Katie. Women in coaching. The Sport Psychologist, Champaign, v. 20, n. 2, p. 222-234, 2006.

LIMA, Rita Matos Teixeira de. Iniciação desportiva de raparigas nos clubes de futebol: estudo da perspectiva de jovens jogadoras, da família e de treinadores. 2013. 197 f. Dissertação (Mestrado em Desporto para crianças e jovens) - Faculdade de Desporto, Universidade do Porto, Porto, 2013.

MEIHY, José Carlos Sebe Bom. Manual de história oral. São Paulo: Loyola, 2005.

MONTEIRO, Igor Chagas; SOARES, João Paulo Fernandes; MOURÃO, Ludmila. Saindo da "posição de impedimento": as árbitras brasileiras no futebol profissional. XIX Congresso Brasileiro de Ciências do Esporte. Anais [...] Vitória: Universidade Federal do Espírito Santo, 2015, p. 1-15.

NASCIMENTO, Aline Santos; NUNES, Mário Luiz Ferrari. A mulher árbitra de futsal: entre a norma e a resistência. Interseções, Rio de Janeiro, v. 16 n. 1, p. 197-216, jun. 2014.

NOVAIS, Mariana Cristina Borges. “À beira do gramado ou fora do jogo?”: as treinadoras do futebol de mulheres no Brasil. 2018. 194 f. Dissertação (Mestrado em Educação Física) Faculdade de Educação Física e Desportos, Universidade Federal de Juiz de Fora, Juiz de Fora, 2018. 
REIS, Fábio Pinto Gonçalves dos; ARRUDA, Ivan Eduardo de Abreu. Mulher, futebol earbitragem: um espaço de conquista, tensão e resistência. Revista EF Deportes, Buenos Aires, v. 16, n. 162, nov. 2011.

ROMERO, Luis Eduardo Medina. The rules can be broken. Nova Iorque: Astro Graphics Design, 1999.

SANTOS, Ineildes Calheiro dos. Escanteio: mulheres que trocam o rosa cultural pelo preto da tradição no campo da arbitragem em futebol. Seminário Internacional Enlaçando

Sexualidades.Anais [...] Salvador: Universidade do Estado da Bahia, 2013, p. 1-15.

SANTOS, Ineildes Calheiro dos; MESSEDER, Suely Aldir. A diferença do desempenho físico e esportivo entre homens e mulheres: um estudo sobre a inserção das mulheres no mundo da arbitragem do futebol brasileiro. In: SEFFNER, F.; CAETANO, M. (org.). Discurso, discursos e contra-discursos latino-americanos sobre a diversidade sexual. Campina Grande: Universidade Federal do Rio Grande, 2016, p. 501-515.

SCOTT, Joan. Gênero: uma categoria útil de análise histórica. Educação e Realidade, Porto Alegre, v. 20, n. 2, p. 71-99, jul./dez. 1995.

SILVA, Alberto Inácio da; RODRIGUEZ-AÑEZ, Ciro Romelio; FRÓMETA, Edgardo Romero. O árbitro de futebol: uma abordagem histórico-crítica. Revista da Educação Física/UEM, Maringá, v. 13, n. 1, p. 39-45, 1. sem. 2002.

SOUZA, Gabriela Conceição de; MOURÃO, Ludmila. Mulheres no tatame: o judô feminino no Brasil. Rio de Janeiro: MAUAD X: FAPERJ, 2011.

STAHLBERG, Lara Tejada. Mulheres em campo: novas reflexões acerca do feminino no futebol. 2011. 125 f. Dissertação (Mestrado em Antropologia Social) - Universidade Federal de São Carlos, São Carlos, 2011.

TAVARES, Marcelo Luís Ribeiro Silva. Mulheres em Manchete: a potência da geração de voleibol dos anos 1980. 2015. 311 f. Dissertação (Mestrado em Educação Física) - Faculdade de Educação Física e Desportos, Universidade Federal de Juiz de Fora, Juiz de Fora, 2015.

\section{NOTAS DE AUTOR}

AGRADECIMENTOS - Não se aplica.

\section{CONTRIBUIÇÃO DE AUTORIA}

Concepção do manuscrito: I.C. Monteiro, L. Mourão.

Coleta de dados: I.C. Monteiro

Análise de dados: I.C. Monteiro, M.C.B. Novais, J.P.F. Soares, L. Mourão

Discussão dos resultados: I.C. Monteiro, M.C.B. Novais, J.P.F. Soares, L. Mourão

Produção do texto: I.C. Monteiro, M.C.B. Novais, J.P.F. Soares, L. Mourão

Revisão e aprovação: L. Mourão

\section{FINANCIAMENTO}

Coordenação de Aperfeiçoamento de Pessoal de Nível Superior (CAPES). 
CONSENTIMENTO DE USO DE IMAGEM - Não se aplica.

\section{APROVAÇÃO DE COMITÊ DE ÉTICA EM PESQUISA}

Aprovado pelo Comitê de Ética em Pesquisa com Seres Humanos da Universidade Federal de Juiz de Fora (UFJF), sob o parecer $n^{\circ}$ CAAE 43035515.5.0000.5147 em 29 de maio de 2015.

CONFLITO DE INTERESSE - Não se aplica.

\section{LICENÇA DE USO}

Os autores cedem à Motrivivência- ISSN 2175-8042 os direitos exclusivos de primeira publicação, com o trabalho simultaneamente licenciado sob a Licença Creative Commons Attribution NonComercial ShareAlike (CC BY-NC SA) 4.0 International. Esta licença permite que terceiros remixem, adaptem e criem a partir do trabalho publicado, desde que para fins não comerciais, atribuindo o devido crédito de autoria e publicação inicial neste periódico desde que adotem a mesma licença, compartilhar igual. Os autores têm autorização para assumir contratos adicionais separadamente, para distribuição não exclusiva da versão do trabalho publicada neste periódico (ex.: publicar em repositório institucional, em site pessoal, publicar uma tradução, ou como capítulo de livro), com reconhecimento de autoria e publicação inicial neste periódico, desde que para fins não comerciais e compartilhar com a mesma licença.

\section{PUBLISHER}

Universidade Federal de Santa Catarina. Programa de Pós-Graduação em Educação Física. LaboMídia - Laboratório e Observatório da Mídia Esportiva. Publicado no Portal de Periódicos UFSC. As ideias expressadas neste artigo são de responsabilidade de seus autores, não representando, necessariamente, a opinião dos editores ou da universidade.

\section{EDITORES}

Mauricio Roberto da Silva, Giovani De Lorenzi Pires, Rogério Santos Pereira.

\section{HISTÓRICO}

Recebido em: 02 de abril de 2020.

Aprovado em: 15 de junho de 2020. 